\title{
Penile Gangrene Due To Priapism: A Case Report
}

\author{
${ }^{1}$ Tabowei BI, MBBS, FMCS, ${ }^{2}$ Kombo BB, MBBS, FRCS, \\ 1. Niger Delta University Teaching Hospital, Okolobiri,Yenagoa,Bayelsa,Nigeria \\ 2. University of Port Harcourt teaching hospital, Port Harcourt,Rivers, Nigeria.
}

\begin{abstract}
Penile gangrene is an infrequently encountered clinical entity in medical practice. Penile gangrene complicating advanced caecal carcinoma is even a rarer disease in this part of the world. We present a case of a 54 year old that had resection of large bowel following carcinoma of the caecum. He presented 6 months later with priapism and gangrene of the gland penis. He had suprapubic cystostomy to relieve the urinary symptoms. Blood was transfused. He had antibiotics and analgesics administered. However, before the penectomy could be performed, he discharged himself again against medical advice.

Key Words: Priapism, penile gangrene,penectomy
\end{abstract}

\section{Introduction.}

Priapism is defined as a prolonged erection of the penis lasting over 6 hours in the absence of sexual stimulation(6). It is a potentially painful condition (1) in which the erect penis or clitoris does not return to its flaccid state, despite the absence of both physical and psychological stimulation. It is a medical emergency and for function to return, early treatment is needed. $(7,8)$

There are two principal types -idiopathic and secondary. $(1,7)$ The principal cause of secondary priapism are the use or abuse of toxic or pharmacological substances,(9) hematological disorders eg $\operatorname{SCD}(10)$, metastatic lesion of the penis by tumour of other origin, pelvic thrombophlibitis, certain neurological disorders and metabolic problems.(11)

Treatment is controversial and often challenging. For function to return, treatment must be quick. Penile gangrene due to priapism is a rare clinical entity.

\section{Case presentation.}

E.O is a 54 year old man who was first seen 7 months prior to presentation with right sided abdominal pains and swelling. He admitted to a history of weight loss, malaise and loss of appetite. He denied a history of change in bowel habit or passage of blood per rectum. Examination done revealed a right sided abdominal mass, mobile and tender to touch.

Abdominal ultrasound done revealed a colonic tumour. He had a right hemi-colectomy and ileo-colic anastomosis done. Postoperatively, he did well and was discharged home for a follow up after a course of chemotherapy. He defaulted. 6 months later, he reported at the hospital-NDUTH, with a two day history of painful erection of the penis. Examination revealed that the penis was erect and painful. He had an emergency shunt procedure(carvenous-saphenous) which resulted in almost complete detumescence. The biochemical and heamatological tests done were within normal limit. He was to have another dose of chemotherapy but discharged self against medical advice when his condition improved.

He reappeared a months later with a two weeks history of painful, persistent erection of the penis, sloughing of the glans penis and inability to pass urine. It was spontaneous in onset, with no known predisposing or precipitating factor. He was not a known sickle cell disease patient and had no trauma to the spine. He occasionally takes some blood capsules prescribed by a chemist and piroxican for pain.

Hemoglobin done was $7 \mathrm{gm}$, Pack cell volume $20 \%$. Electrolytes, urea and Creatinine done was essentially normal. Abdominal scan was requested for but could not be done. The liver function test (LTF), and platelet count were also requested for but were not done due to financial constraints. He was to have a course of adjunct chemotherapy(Cyclophosphomide, 5-flourouracil, Adramycin) and penectomy was offered. He had suprapubic cystostomy to relieve the urinary symptoms.

Blood was transfused. He had antibiotics and analgesics administered. However, before the procedure could be performed, he discharged himself again against medical advice.

\section{Discussion}

Malignant priapism is a term first used by Peacock in 1938 to describe, non-sexual erections caused by invasion of malignant cells into the cavernosal sinuses and their associated venous systems.(12) Priapism of metastatic origin is a very rare disease entity in medical practice. It represents 3-8\% of all cases of priapism. 
Obstruction to penile venous flow or tumour cell infiltration of the corpora carvenosa may be responsible. $(13,14)$.

From the available literature, penile gangrene complicating priapism is even a rarer disease condition.(1) Penile gangrene from priapism has been associated with diabetic mellitus,(15) chronic renal failure in patient on dialysis, self inflicted penile gangrene,etc, but rare with metastatic colonic tumours. Despite the rich blood supply to the penis, malignant metastasis to the penis are a rare(16) and even rarer cause of priapism.(13) Primary pelvic tumour from bladder and prostate are usually the commonest sites for secondaries to the penis(16). Priapism may be the initial mode of presentation in as much as $40-50 \%$ of malignant penile metastasis,(17) but not with gangrene as was demonstrated in this case.

In the case reported, the patient has had a colonic tumour resected, and had only a course of chemotherapy and could not carry out all the required investigations done.( due to financial constraints). He however had a shunt procedure done at initial presentation which gave him temporal relieve for a few weeks.

Para-neoplastic syndrome occurs in about $11 \%$ of patient with malignant disease.(18) The onset of priapism and the gangrene of the glans penis indicates a para-neoplastic syndrome or metastatic penile disease. This could not be proven in this case as a result of the absence of a full clinical imaging, chemical and hematological evaluating investigative tools.

The management of priapism of neoplastic origin is controversial. $(9,13$,$) The treatment modalities$ depends on patients clinical condition and the prognosis and are almost always palliative.(1,19), The treatment options available are chemotherapy, radiotherapy, cavernosum/spongiosum short-circuit, urinary diversion through cystostomy, and partial or total phallectomy.(20) This is because, the patients do not usually respond to conservative measures (sympathomimetic drugs) or to shunt procedures used in cases of priapism secondary to other causes. Our patient had a shunt procedure done, but his condition reoccurred after a few weeks. This is in agreement with other reports.

In general, priapism secondary to neoplastic infiltrative disease is indicative of a poor prognosis. $(1,21)$ It has a low survival rate of one year after appearance of the condition.(22) Partial or total penectomy, chemotherapy, radiotherapy are all treatment options. Conservative and supportive measures are all useful treatment modalities due to the advanced nature of the metastatic penile priapism.

Most patient with penile metastasis have widely disseminated disease, and over $80 \%$ of the patient will die within 6 months, irrespective of the primary tumour and the treatment method making palliative noninvasive treatment advisable.(14) Our patient had in addition to priapism, penile gangrene and urinary retention. The only available option was penectomy and suprapubic cystostomy.

The treatment options for penile metastatic diseases are always palliative but with the addition of gangrene and urinary retention, penectomy and suprapubic cystostomy are the only available option. $(12,13,14)$

We offered the patient penectomy based on his clinical condition but he refused. To relieve pains due to urinary obstruction, he had a suprapubic cystostomy which yielded clear urine.

That our patient discharged himself to a spiritual home against medical advice despite adequate counseling, which is a recurrent feature in our society. Ignorance and the poor belief pattern by Africans about the etio-pathology of disease in general and belief in miracles and quick cure of all diseases by traditional herbalist and spiritualist.

\section{Conclusion}

Priapism leading to penile gangrene has been described as a hallmark of severe systemic vascular disease. The present case report does not fit into one of the common cause of penile gangrene. We report a case of painful and gangrenous priapism secondary to penile metastasis of a caecal carcinoma. Penectomy was offered but patient refused further treatment and discharged himself against medical advice. 


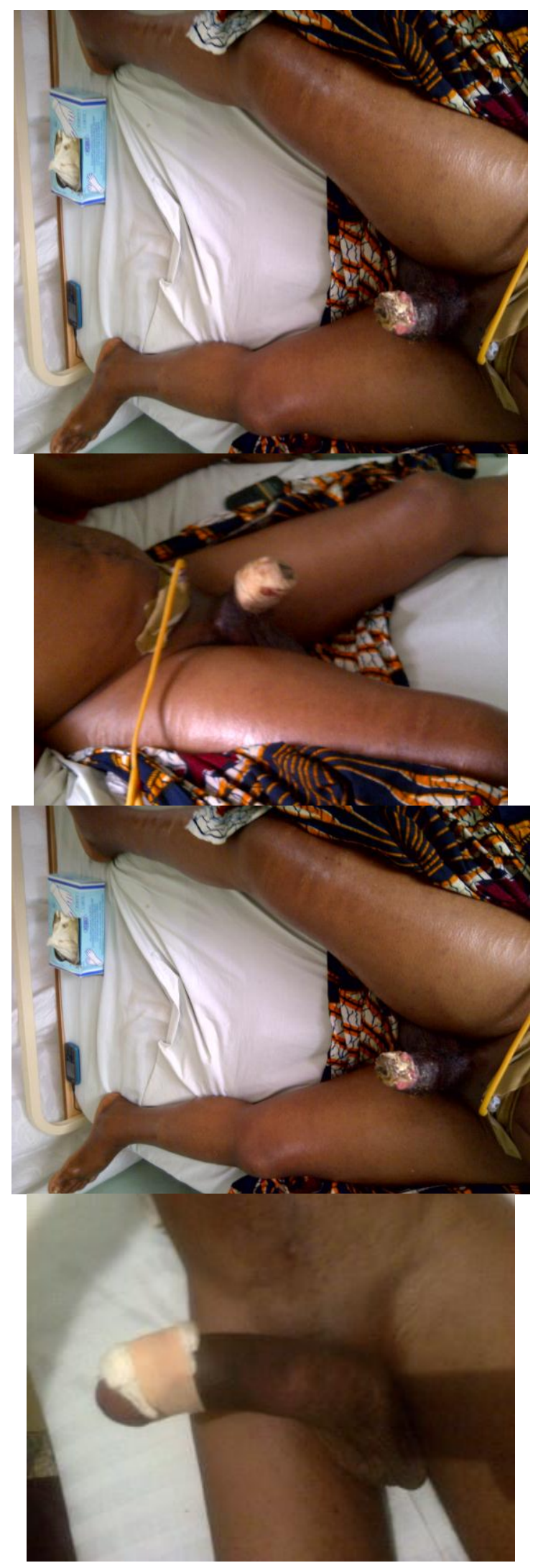




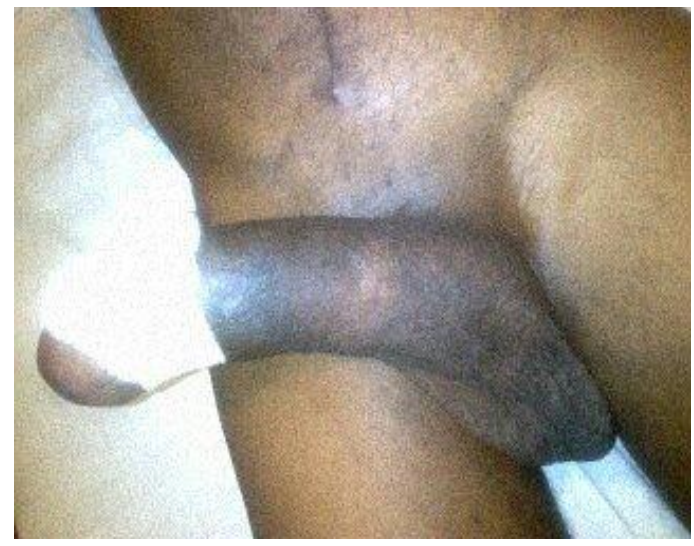

References

[1]. Abduiwahab A, Ajape, Ahmad Bello. Penile gangrene: An unusual complication of priapism in a patient with Bladder carcinoma. Journal of surgical Technique and case report. 2011, vol 3,(1) 37-39.

[2]. Harris FC, Mydlo JH. Ischaemic and gangrene of penis. J Urol. 2003;169: 1795.

[3]. Kwok B, Varol C, Priapism and penile gangrene due to thrombotic thrombocytopenic purpura. Urology 2000;75:71-72.

[4]. Olaomi OO. Penile gangrene following cavernoglandular shunt for priapis: case report. Niger.J Surg Res 2002;4: 112-3.

[5]. Khoriaty N, Shick E. Penile gangrene :An unusual complication of priapism. How to avoid it?. Urology 1980; 16:280-3.

[6]. Keoghane SR, Sullivan ME, Millar MAW. The aetiology, pathogenesis and management of priapism. BJU international 2000; 90(2): 149-154.

[7]. Badmus TA, Adediran IA, Adesunkanmi AR,Katung IA. Priapism in southwest Nigeria. East Afr Med J, 2003 80(10)518-24.

[8]. Aghaji AE. Priapism in adult Nigerias. BJU int. 2000, 85(4): 493-5.

[9]. Guvel S, KilincF, Torun D, Egilmez T, Ozkardes H. malignant priapism secondary to Bladder cancer. Journal of Andrology 2003, 24(4): 499-500.

[10]. Brain F B, Joseph JP. Sickle cell trait and priapism: a case report and review of the literature. Cases J. 2008,1 : 429.

[11]. Ana CD, Jacques PM, et al. Priapism secondary to contiguity bladder carcinoma infiltration of the penis. Actas Urologicas Espanolas @009; 33(3): 327-329..

[12]. DubocqFM, Tefili MV, Grignon DJ, et al. High flow malignant priapism with isolated metastasis to the corpora. Urology. 1998;51: 324-326.

[13]. Chan PTK, Begin LR, Arnold D, et al. priapism secondary to penile matastasis: a case report of two case and a review of the literature. J surg Oncol. 1998; 68:51-59.

[14]. Yu-Hsiang L, Jerry JK, et al. malignant priapism secondary to matestatic prostate cancer: A case report and Review of literature. Rev Urol 2011; 13(2): 90-94.

[15]. Vijayan P. Gangrene of the penis in a diabetic male with multiple amputations and follow up. J Urol. 2009; 25: 123-5.

[16]. Jacob Cherian, Sreekumar J, Ali T, et al. Secondary penile tumours revisited. Int Semin Surg Oncol 2006; 3:33.

[17]. Abeshouse BS, Abeshouse GA. Metastetic tumours of the penis: A review of the literature and a report of two cases. J Urol. 1961; 86: 99.

[18]. Rickles FR, Edward RL. Activation of blood coagulation in cancer. Trousseau's syndrome revisited. Blood 1983; 62:14-31.

[19]. Tae Sung et al. synchronous penile metastasis from a rectal carcinoma. Int J Colorectal Dis. 2008 ; 23(3):333-4.

[20]. Escolona M, Martinez CJ, et al. A proposito de tres casos. Actas Urologicas Espanolas 1993; 17(7): 461-3.

[21]. Phlip J, Mathew J, Penile metastatic of prostatic adenocarcinoma: report of two cases and reveiew of literature. World J Surg Oncolo. 2003;1: 16.

[22]. Trevex MA, Aranda JM et al, Transitional carcinoma and malignant priapism. Actas Urologicas espanoles 2004; 28990:698 697. 